\title{
Whole brain radiation therapy alone versus radiosurgery for patients with 1-10 brain metastases from small cell lung cancer (ENCEPHALON Trial): study protocol for a randomized controlled trial
}

Denise Bernhardt ${ }^{1,2^{*}}$ (D) Adriane Hommertgen ${ }^{1,2}$, Daniela Schmitt ${ }^{1,2}$, Rami El Shafie ${ }^{1,2}$, Angela Paul ${ }^{1,2}$, Laila König ${ }^{1,2}$, Johanna Mair-Walther ${ }^{8}$, Johannes Krisam ${ }^{9}$, Christina Klose ${ }^{9}$, Thomas Welzel ${ }^{1,2}$, Juliane Hörner-Rieber ${ }^{1,2}$,

Jutta Kappes ${ }^{4}$, Michael Thomas ${ }^{3,7}$, Claus Peter Heußel ${ }^{7,8,9}$, Martin Steins ${ }^{3,7}$, Meinhard Kieser ${ }^{9}$, Jürgen Debus ${ }^{1,2,5,6}$ and Stefan Rieken ${ }^{1,2}$

\begin{abstract}
Background: Conventional whole brain radiotherapy (WBRT) has been established as the treatment standard in patients with cerebral metastases from small-cell lung cancer (SCLC), however, it has only modest efficacy and limited prospective data is available for WBRT as well as local treatments such as stereotactic radiosurgery (SRS).

Methods/design: The present single-center prospective randomized study, conducted at Heidelberg University Hospital, compares neurocognitive function, as objectively measured by significant deterioration in Hopkins Verbal Learning Test - Revised total recall at 3 months. Fifty-six patients will be randomized to receive either SRS of all brain metastases (up to ten lesions) or WBRT. Secondary endpoints include intracranial progression (local tumor progression and number of new cerebral metastases), extracranial progression, overall survival, death due to brain metastases, local (neurological) progression-free survival, progression-free survival, changes in other cognitive performance measures, quality of life and toxicity.
\end{abstract}

Discussion: Recent evidence suggests that SRS might be a promising treatment option for SCLC patients with brain metastases. The present trial is the first to prospectively investigate the treatment response, toxicity and neurocognition of WBRT and SRS in SCLC patients.

Trial registration: Clinicaltrials.gov NCT03297788. Registered September 29, 2017.

Keywords: Small-cell lung cancer, Brain metastases, Stereotactic radiosurgery, Whole brain radiotherapy

\section{Background}

Patients suffering from small cell lung cancer (SCLC) are at high risk for developing brain metastases (BM) during the course of their disease. Between $40 \%$ and $50 \%$ of patients develop BM until time of death [1] and the risk of developing $\mathrm{BM}$ further increases with

\footnotetext{
* Correspondence: denise.bernhardt@med.uni-heidelberg.de

'Department of Radiation Oncology, University Hospital Heidelberg, INF 400, 69120 Heidelberg, Germany

${ }^{2}$ Heidelberg Institute of Radiation Oncology (HIRO), Heidelberg, Germany Full list of author information is available at the end of the article
}

prolonged survival [2]. Prophylactic cranial irradiation (PCI) is offered to limited disease patients if they respond to first line regime [3-5]. However, up to $10-$ $15 \%$ of patients present with BM at initial diagnosis [6-8], and if magnetic resonance imaging (MRI) is used as a diagnostic tool for initial staging, the proportion increases to $15-20 \%$ [9]. Treatment options are usually limited to whole brain radiotherapy (WBRT) and palliative chemotherapy [10]. The actual effect of therapeutic WBRT has mainly been studied

(c) The Author(s). 2018 Open Access This article is distributed under the terms of the Creative Commons Attribution 4.0 International License (http://creativecommons.org/licenses/by/4.0/), which permits unrestricted use, distribution, and 
in small retrospective and non-randomized studies [2, 11-15]. Moreover, patients within recursive partitioning analysis (RPA) class III were commonly excluded from any prospective BM trials that involved WBRT $[16,17]$. In a recent Japanese trial, prophylactic cranial irradiation did not result in longer overall survival compared with observation plus regular MRI follow-ups in patients with extensive disease (ED) SCLC [18]. PCI is therefore no longer recommended for patients with ED SCLC [19] when patients undergo regular MRI brain scans during follow-up [18]. Therefore, the number of patients with oligometastasic cerebral disease might rise.

The present trial aims to investigate the treatment response to 'conventional whole brain radiotherapy' and 'stereotactic radiotherapy' (SRS) in SCLC patients. The primarily investigated endpoint is neurocognitive function, as objectively measured by significant deterioration in Hopkins Verbal Learning Test - Revised (HVLT-R) total recall at 3 months [20]. Secondary endpoints include intracranial progression (local tumor progression, number of new cerebral metastases), extracranial progression, overall survival, death due to brain metastases, local (neurological) progression-free survival, progression-free survival, changes in other cognitive performance measures, quality of life, and toxicity.

\section{Methods/design}

The study is a randomized phase II study with two study arms. The standard arm is WBRT and the experimental arm is SRS (Fig. 1). We hypothesized that patients treated with WBRT would have inferior neurocognitive function based on the HVLT-R [20] compared with patients treated with SRS alone.

\section{Recruitment and randomization}

Eligible patients who present at the Departments of Radiation Oncology, University Hospital Heidelberg, Germany, will be recruited to the study. Eligibility requirements are:

\section{Inclusion criteria}

- Histologically confirmed ED SCLC

- MRI-confirmed cerebral metastasis (not resected, maximum number of 10)

- Age $\geq 18$ years of age

- For women with childbearing potential (and men), adequate contraception

- Ability of subject to understand character and individual consequences of the clinical trial

- Written informed consent (must be available before enrolment in the trial)

\section{Exclusion criteria}

- Refusal of the patients to take part in the study

- Previous radiotherapy of the brain

- Patients who have not yet recovered from acute high-grade toxicities of prior therapies

- Known carcinoma $<5$ years ago (excluding carcinoma in situ of the cervix, basal cell carcinoma, squamous cell carcinoma of the skin) requiring immediate treatment interfering with study therapy

- Pregnant or lactating women

- Participation in another clinical study or observation period of competing trials, respectively

- MRI contraindication (i.e., cardiac pacemaker, implanted defibrillator, certain cardiac valve replacements, certain metal implants)

\begin{tabular}{|c|c|c|c|c|c|c|c|}
\hline \multirow[t]{3}{*}{ Work-Flow } & \multirow{2}{*}{$\begin{array}{l}\text { Baseline } \\
\text { T0 }\end{array}$} & \multicolumn{2}{|l|}{ Therapy } & \multicolumn{4}{|l|}{ Follow-up } \\
\hline & & Start & End & T1 & $\mathrm{T} 2$ & T3 & T4 \\
\hline & $\begin{array}{l}\text { Baseline visit } \\
\text { after } \\
\text { enrollment }\end{array}$ & $\begin{array}{l}\text { Day } 1 \text { of } \\
\text { RT }\end{array}$ & $\begin{array}{l}\text { Last day of } \\
\text { RT }\end{array}$ & $\begin{array}{l}3 \text { months after } \\
\text { T0 }\end{array}$ & $\begin{array}{l}6 \text { months } \\
\text { after T0 }\end{array}$ & $\begin{array}{l}9 \text { months } \\
\text { after T0 }\end{array}$ & $\begin{array}{l}12 \text { months } \\
\text { after T0 }\end{array}$ \\
\hline Medical history & $\mathrm{X}$ & & & $\mathbf{X}$ & $\mathrm{X}$ & $\mathrm{X}$ & $\mathrm{X}$ \\
\hline $\begin{array}{l}\text { Nerocognitive Testing } \\
\text { (HVLT-R, PAL, RTI, } \\
\text { SWM) }\end{array}$ & $\mathbf{x}$ & & & $\mathrm{x}$ & $\mathbf{x}$ & $\mathbf{x}$ & $\mathrm{x}$ \\
\hline MRI & $\mathrm{x}$ & & & $\mathbf{x}$ & $\mathbf{x}$ & $\mathbf{x}$ & $\mathrm{X}$ \\
\hline $\begin{array}{l}\text { Planning CT with and } \\
\text { w/out i.v. contrast }\end{array}$ & $\mathrm{x}$ & & & & & & \\
\hline $\begin{array}{l}\text { EORTC QoL brain } \\
\text { Module (BN20) and } \\
\text { PAL }\end{array}$ & $\mathrm{x}$ & & & $\mathbf{x}$ & $\mathrm{x}$ & $\mathbf{x}$ & $\mathrm{x}$ \\
\hline $\begin{array}{l}\text { Documentation of } \\
\text { medication }\end{array}$ & $\mathbf{X}$ & & $\mathbf{x}$ & $\mathbf{x}$ & $\mathbf{x}$ & $\mathbf{X}$ & $\mathrm{X}$ \\
\hline $\begin{array}{l}\text { Clinical, neurological } \\
\text { examination }\end{array}$ & $\mathrm{x}$ & & $\mathbf{x}$ & $\mathbf{x}$ & $\mathrm{x}$ & $\mathbf{X}$ & $\mathrm{x}$ \\
\hline
\end{tabular}

Fig. 1 Intervention and assessment schedule for the ENCEPHALON trial 
- Karnofsky Performance Score $<60$

- Simultaneous cytotoxic chemotherapy

- Last application of chemotherapy/immunotherapy/ targeted therapy $<1$ week before cerebral radiotherapy

After meeting eligibility criteria, 56 patients will be randomly assigned to SRS or WBRT. To achieve comparable intervention groups, patients will be allocated in a concealed fashion in a $1: 1$ ratio by means of randomization using a centralized web-based tool (www.randomizer.at). Randomization will be stratified with respect to time of appearance (synchronous vs. metachronous). Block randomization with varying block lengths will be performed to achieve equal group sizes in total. BM are defined as synchronous if discovered at the time of initial diagnosis of the primary tumor or within 3 months thereafter. All other patients will be classified as metachronous.

\section{Assessment of the primary and secondary endpoints}

The primary endpoint is neurocognition after cerebral irradiation in SCLC patients treated with WBRT or SRS, defined as a drop of at least 5 points from baseline in HVLT-R total recall at 3 months. Secondary objectives are intracranial progression (local tumor progression, number of new cerebral metastases), extracranial progression, overall survival, death due to brain metastases, local progression-free survival, progression-free survival, changes in other cognitive performance measures, quality of life, and toxicity.

Time to progression is defined as the number of days from randomization to the first occurrence of the respective event. Overall survival time is defined as number of days from randomization until death or end of follow-up. For patients alive at the end of the study, the overall survival time will be censored at the time of the last visit or follow-up contact.

Time to death due to $\mathrm{BM}$ is defined as number of days from randomization until death due to $\mathrm{BM}$ or end of follow-up, where death due to BM is defined as death with intracranial progression as a component of cause of death. Locally progression-free survival time is defined as number of days from randomization until local tumor progression, death without prior local progression, or end of follow-up. The occurring events of interest will be classified as (1) progression of cerebral metastases present at baseline only, (2) occurrence of new cerebral metastases only, (3) simultaneous detection of progression of cerebral metastases present at baseline and of new metastases, and (4) death without local progression.

Time to extracranial progression is defined as number of days from randomization until extracranial progression or end of follow-up, where extracranial progression is the first date on which progressive disease outside the brain occurred according to the physician treating the primary disease. Progression-free survival time is defined as number of days from randomization until the first occurrence of intracranial or extracranial progression, death without prior progression, or end of follow-up. Intracranial progression is defined as occurrence of progressive disease concerning the pre-existing BM or the occurrence of new BM.

Local tumor progression (progressive disease, PD) is defined as occurrence of intracranial progression) in the area of the SRS.

Progression in the WBRT area is defined as occurrence of intracranial tumor progression (progression of existing lesions and/or occurrence of new lesions).

The European Organization for Research and Treatment of Cancer (EORTC) Questionnaire including brain module (BN20) and the EORTC Paired Associated Learning Questionnaire will be used. This study will use the International Common Terminology Criteria for Adverse Events (CTCAE) version 4.0 for toxicity and adverse event reporting.

Patients are followed within the trial protocol for 12 months after baseline visit (T0). After T0, patients are scheduled for follow-up visits every 3 months or as needed clinically, including contrast-enhanced MRI as well as thorough clinical-neurological assessment. Formal neurocognitive testing and quality of life instrument testing will be performed at baseline and during follow-up visits every 3 months. The computer-administered Cambridge Neuropsychological Test Automated Battery (CANTAB) will be used to examine specific components of cognition. The participants will be instructed to respond to stimuli presented on a computer screen by pressing a touch screen. Three tests were chosen to evaluate further neurocognitive changes: Paired Associated Learning for paired Associates Learning assesses visual memory and new learning [21]; Reaction Time to provide assessments of motor and mental response speeds [22], as well as measures of movement time, reaction time, response accuracy and impulsivity. Further, Spatial Working Memory will be used [22], which requires retention and manipulation of visuospatial information. Staff members administering the tests were trained and approved by the clinical neuropsychologist in the project group.

For the last patient in, the final study visit will be 12 months after baseline. This is considered the final study visit (last patient out). All other patients will be followed regularly as described in detail until death or until 12 months after baseline. Beyond that, all patients can be followed within routine clinical visits according to national guidelines and survival and progression data will be documented until 'last patient out'. If death occurs at less than 12 months or patients leave the study prior to 12 months, they will be still included into the intention-to-treat population. 


\section{Radiotherapy}

\section{Treatment planning for WBRT}

For WBRT, patients will be immobilized using an individually manufactured head mask. For treatment planning, computed tomography (CT) without contrast, contrast-enhanced CT as well as MRI will be performed for optimal target definition. The target volume includes the whole brain. WBRT will be delivered by opposed lateral $6 \mathrm{MeV}$ photon beams. Dose constraints of normal tissue will be respected according to QUANTEC reports [23, 24]. WBRT will be applied in 10 once-daily fractions each of $3 \mathrm{~Gy}$, to a total dose of $30 \mathrm{~Gy}$ in 10 fractions to the whole brain.

\section{Treatment planning for SRS}

MRI and CT imaging are 3-dimensionally fused using a validated non-elastic imaging fusion algorithm and the fusion results are cross-checked by an experienced physician and adapted if necessary.

Organs at risk are contoured and adapted on the basis of CT scans and MRI. For target delineation, a gross target volume (GTV) and a planning target volume (PTV) are contoured. The basis for GTV definition is the contrast-based, T1-weighted, three-dimensional MPRAGE sequence. The GTV consists of all contrast-enhanced tissue associated with the target lesion and all additional tissue judged by an experienced physician to be part of the suspect target lesion (e.g. non-contrast-enhanced necrotic tissue within or adjoining cystic metastatic lesions). To the GTV, a PTV margin of $1 \mathrm{~mm}$ is added by isotropic expansion that can be slightly modified if deemed necessary by the treating physician (e.g., intersection with adjoining organs at risk).

Treatment planning for SRS will be performed using Accuray's Multiplan or subsequent approved treatment planning systems for CyberKnife .

SRS will be applied in one to a maximum of six fractions. For SRS, the dose prescription to the PTV will be as follows (risk adapted SRS dose prescription volume and location based):

- 20 Gy to the $70 \%$-isodose (lesions $<2 \mathrm{~cm}$ max. diameter)

- 18 Gy to the 70\%-isodose (lesions 2-3 cm max. diameter)

- $6 \times 5$ Gy to the conformally surrounding isodose (lesions $>3 \mathrm{~cm}$ max. diameter or brain stem)

Dose constraints of normal tissue will be respected according to QUANTEC reports [23, 24] and extensive clinical experience at our institution.

\section{Statistical analysis}

The primary hypothesis of the trial is that there is a difference between the two treatment arms with respect to the primary endpoint, defined as a drop of at least 5 points from baseline in HVLT-R total recall at 3 months after baseline (T0). Chang et al. [25] observed deterioration probabilities of 0.64 for SRS + WBRT and 0.20 for SRS alone at 4 months after baseline. Based on those results, assuming a deterioration probability of 0.20 for the SRS arm and 0.64 for the WBRT arm in our trial, $n=19$ patients per arm are required to demonstrate a difference between treatment arms applying a $\chi^{2}$ test at a two-sided significance level of $\alpha=0.05$ with a probability of $1-\beta=0.8$. Assuming exponentially distributed survival times with a median of 6 months for both groups, 29.3\% of all randomized patients are expected to have died before the measurement of the primary endpoint. Thus, $n=28$ patients per group are required to yield a sufficiently high power for a comparison of the deterioration rate within the two groups. Statistical analysis is based on the International Conference on Harmonization Guidelines Structure and Content of Clinical Study Reports and Statistical Principles for Clinical Trials. A detailed methodology for the statistical analysis will be described in the statistical analysis plan, which will be finalized before database lock. Statistical analysis will be performed using SAS v9.4 or higher.

\section{Efficacy evaluation}

The primary hypothesis of the trial is that there is a difference between the two treatment arms with respect to the primary endpoint, defined as a drop of at least 5 points from baseline in HVLT-R total recall at 3 months. With $\pi_{\text {SRS }}$ being the deterioration probability in the SRS arm and $\pi_{W B R T}$ being the deterioration probability in the WBRT arm, the null hypothesis $\mathrm{H}_{0}: \pi_{\mathrm{SRS}}=\pi_{\mathrm{WBRT}}$ is tested against its alternative $\mathrm{H}_{1}: \pi_{\mathrm{SRS}} \neq \pi_{\mathrm{WBRT}}$ at a two-sided significance level of $\alpha=0.05$ using a Cochran-MantelHaenszel test adjusting for the confounder time of appearance (synchronous vs. metachronous). Missing data for the primary outcome variable will be replaced by using multiple imputation which takes the covariates of treatment group, time of appearance (synchronous vs. metachronous), and the baseline HVLT-R total recall score into account by application of the fully conditional specification method [26]. For the secondary time-to-event endpoints overall survival, local progression-free survival, and locoregional progression-free survival, median event times and 1-year rates will be given with $95 \%$ confidence intervals and Kaplan-Meier curves will be calculated for both treatment groups. A (descriptive) log-rank test stratified for time of appearance (synchronous vs. metachronous) will be performed in order to assess differences between the two treatment groups, and a descriptive $P$ value will be given. A Cox proportional hazard model with overall 
survival as dependent variables well as treatment group and time of appearance as independent factors will be fitted to estimate the hazard ratio for the treatment group together with a $95 \%$ confidence interval.

All further secondary outcomes will be analyzed descriptively, and descriptive $P$ values will be reported together with corresponding 95\% confidence intervals.

\section{Ethical issues, information, and safety}

The study protocol, Patient Information sheet, and Declaration of Informed Consent was approved by the Heidelberg University Ethics Committee (S-470/2017). The procedures described in the submitted study protocol regarding the performance, evaluation, and documentation of this study has been selected in such a way that the principles of the Good Clinical Practice (GCP) guidelines are observed. The regulations regarding medical confidentiality and data protection are fulfilled. Informed consent will be obtained from all participants in the study.

Concerning radiation protection law (StrSchV), the authors of this protocol presume that a submission to the Bundesamt für Strahlenschutz (BfS) is not required. To confirm this position, the investigators submitted this protocol to the expert commission of the German Society of Radiation Oncology ENCEPHALON Clinical Trial Protocol Version 1.0, Date 07/2017 (DEGRO No. 132) (Additional file 1; SPIRIT Checklist).

\section{Discussion}

The primary aim of this trial is to exploratively investigate the effect of SRS compared to WBRT in patients with BM from SCLC. Currently, according to national guidelines, the recommendation for patients with $\mathrm{BM}$ from SCLC, regardless of the number of BM, is WBRT [10]. The actual evidence behind those recommendations is low and mainly based on retrospective studies from the last three decades and is analogically reasoned by previous PCI studies [3-6, 27]. In a recent Japanese trial, prophylactic cranial irradiation did not result in longer overall survival compared with observation in patients with ED SCLC and PCI is therefore no longer recommended for patients with extensive disease SCLC when patients receive regular MRI examinations during follow-up. Furthermore, if SCLC patients are regularly checked with MRI, the actual number of patients with limited number of BM might rise. The general use of WBRT in SCLC patients is additionally supported by the general paradigm of a diffuse intracranial disease pattern; even so, these beliefs derive from a pre-MRI era. The EORTC conducted a prospective, phase II study between 1989 and 1995 that included patients $(n=22)$ with brain-only metastases SCLC to evaluate the efficacy of WBRT [28]. The median response duration in patients with an objective response was 5.4 months, and the median survival of all patients was 4.7 months. A number of retrospective studies investigated prognostic factors and identified subgroups of SCLC patients with a favorable prognosis [15, 29-31]. In a recent report [5], we investigated 229 SCLC patients with BM from SCLC; median overall survival after WBRT was 6 months. The main prognostic factors associated with overall survival were performance status, time of appearance of intracranial disease (synchronous vs. metachronous), initial response to chemotherapy, and higher RPA class. Interestingly, patients in RPA class I showed a median survival after WBRT of 17 months and had a comparable outcome to patients with non-cerebral disease treated with PCI. Furthermore, 39\% of patients had 1-5 $\mathrm{BM}$ and the majority of patients received staging with cerebral MRI prior to treatment [32]. The recently developed disease-specific prognostic score for patients with BM from SCLC was even more prognostic than RPA score and diagnosis-specific graded prognostic assessment score [29] and revealed a subgroup of patients with a very short survival (class I) and a subgroup with a favorable prognosis (class II) [33]. The disease-specific prognostic score for patients with BM from SCLC will be validated within the ENCEPHALON trial. Because of the multiple prognostic factors and differences in outcomes in patients with BM from SCLC, a one- fits-all treatment framework, in which all patients are automatically recommended for WBRT, is no longer appropriate and the actual evidence for this recommendation is missing.

Radiosurgery and surgery are possible treatment options in patients with a limited number of BM and for patients with $\mathrm{BM}$ of less than $3 \mathrm{~cm}$ in diameter from solid tumors, except SCLC patients. For patients with 2-4 metastases and with a life expectancy of more than 3 months, radiosurgery should be used rather than WBRT [34-38]. A recent Japanese trial investigated the effect of SRS in 1194 patients with multiple brain metastases from solid tumors. The authors concluded that SRS in patients with 5-10 $\mathrm{BM}$ is non-inferior to that in patients with $2-4 \mathrm{BM}$. Considering the minimal invasiveness of stereotactic radiosurgery and the fewer side effects than with WBRT, SRS might be a suitable alternative for patients with up to 10 brain metastases [39].

For SCLC patients there is only limited prospective data available regarding locally ablative treatments or SRS. However, a number of retrospective studies investigated the effect of SRS as a treatment in a primary setting and as a salvage option after prior WBRT or PCI in SCLC patients [32, 40-44]. Patients who received SRS instead of WBRT showed a comparable or even better survival compared to patients with WBRT. This is, of course, biased by the retrospective design and the limited number of $\mathrm{BM}$ in the patient group that received 
SRS. On the other hand, this implies that a subgroup of patients might be suitable for SRS. In a prospective cohort trial, Li et al. [45] evaluated SRS versus SRS + WBRT and WBRT alone in patients with a single BM of SCLC or non-SCLC. The study did not reveal a statistically significant difference concerning median survival (9.3 vs. 10.6 months) or recurrence and progression. The authors concluded that SRS-alone and SRS + WBRT seem superior to WBRT-alone in prolonging overall survival, local control, and improving quality of life in patients with single BM from lung carcinoma.

Chang et al. [25] prospectively evaluated neurocognitive outcome in 58 patients with 1-3 BM from solid tumors and were randomly assigned to SRS + WBRT or SRS alone. The primary endpoint was neurocognitive function measured as a significant deterioration (5-point drop compared with baseline) in HVLT-R total recall at 4 months. After 58 patients were recruited, the trial was stopped on the basis that there was a high probability $(96 \%)$ that patients receiving SRS plus WBRT were significantly more likely to show a decline in learning and memory function at 4 months than patients assigned to receive SRS alone. SCLC patients often die from thoracic progression, rather than of progression of BM. Therefore, especially for a patient group with a favorable prognosis, the preservation of cognitive function and quality of life is essential.

\section{Trial status}

Recruiting.

\section{Additional file}

Additional file 1: SPIRIT 2013 Checklist: Recommended items to address in a clinical trial protocol and related documents*. (PDF $205 \mathrm{~kb}$ )

\section{Abbreviations \\ BM: brain metastases; CT: computed tomography; ED: extensive disease; EORTC: European Organization for Research and Treatment of Cancer; GTV: gross target volume; HVLT-R: Hopkins Verbal Learning Test - Revised; MRI: magnetic resonance imaging: PCl: prophylactic cranial irradiation PTV: planning target volume; RPA: recursive partitioning analysis; SCLC: small cell lung cancer; SRS: stereotactic radiotherapy; WBRT: whole brain radiotherapy}

\section{Acknowledgements}

This work was supported by a Heidelberg University young investigator grant to DB.

We thank our study nurses Renate Haselmann, Karen Lossner, and Alexandros Gioules for the support of this trial.

\section{Funding}

This trial has received funding within a competitive and peer-reviewed research grant financed by Accuray Inc., Sunnyvale California. The funding source has no role in study design, data collection, data analysis, data interpretation, or writing of the report.

Availability of data and materials

The data used in this analysis is from publications available in the public domain.

\section{Authors' contributions}

DB developed and planned this trial under the supervision of JD, MT, MS, and $S R$, who is the principal investigator. DB, RES, JH-R, AP, JK, and LK perform patient treatment and clinical assessments. TW and $\mathrm{CPH}$ are the supervising diagnostic radiologists. DS is responsible for treatment planning, dosimetry, and plan verification. JK and MK are the trial statisticians and responsible for statistical planning and statistical analysis. CK is responsible for data management. JM-W is responsible for neurocognitive testing. AH coordinates the study. All authors read and approved the final manuscript.

Ethics approval and consent to participate

The Heidelberg Ethics Committee approved this study on (S-470/2017) Consent to participate/informed consent will be obtained from all participants in the study.

Consent for publication

Not applicable.

\section{Competing interests}

The authors declare that they have no competing interests.

\section{Publisher's Note}

Springer Nature remains neutral with regard to jurisdictional claims in published maps and institutional affiliations.

\section{Author details}

'Department of Radiation Oncology, University Hospital Heidelberg, INF 400, 69120 Heidelberg, Germany. ${ }^{2}$ Heidelberg Institute of Radiation Oncology (HIRO), Heidelberg, Germany. ${ }^{3}$ Department of Thoracic Oncology. Translational Lung Research Centre Heidelberg (TLRC-H), Thoraxklinik, Heidelberg University, Heidelberg, Germany. ${ }^{4}$ Department of Pneumology, Thoraxklinik, Heidelberg University, Heidelberg, Germany. ${ }^{5} \mathrm{Clinical}$ Cooperation Unit Radiation Oncology, German Cancer Research Center (DKFZ), Im Neuenheimer Feld 280, 69120 Heidelberg, Germany. ${ }^{6}$ Heidelberg Ion-Beam Therapy Center (HIT), Im Neuenheimer Feld 450, 69120 Heidelberg, Germany. ${ }^{7}$ Translational Lung Research Centre Heidelberg (TLRC-H), German Centre for Lung Research (DZL), Heidelberg, Germany. ${ }^{8}$ Department of Neurooncology, University Hospital of Heidelberg, Im Neuenheimer Feld 672, 69120 Heidelberg, Germany. ${ }^{9}$ Institute of Medical Biometry and Informatics, University of Heidelberg, Im Neuenheimer Feld 130.3, 69120 Heidelberg, Germany.

Received: 8 January 2018 Accepted: 15 June 2018

Published online: 16 July 2018

References

1. Postmus P. Brain Metastases From Small Cell Lung Cancer: Chemotherapy, Radiotherapy, or Both? Semin Radiat Oncol. 1995;5:69-73. https://doi.org/10. 1054/SRAO00500069.

2. Nugent IL, Bunn PA, Matthews MJ, Ihde DC, Cohen MH, Gazdar A, et al. CNS metastases in small cell bronchogenic carcinoma: increasing frequency and changing pattern with lengthening survival. Cancer. 1979:44:1885-1893. http://www.ncbi.nlm.nih.gov/pubmed/227582. Accessed 23 Aug 2016.

3. Slotman B, Faivre-Finn C, Kramer G, Rankin E, Snee M, Hatton M, et al. Prophylactic cranial irradiation in extensive small-cell lung cancer. N Engl J Med. 2007;357:664-72. https://doi.org/10.1056/NEJMoa071780.

4. Aupérin A, Arriagada R, Pignon JP, Le Péchoux C, Gregor A, Stephens RJ, et al. Prophylactic cranial irradiation for patients with small-cell lung cancer in complete remission. Prophylactic Cranial Irradiation Overview Collaborative Group. N Engl J Med. 1999;341:476-84. https://doi.org/10.1056/ NEJM199908123410703.

5. Bernhardt D, Adeberg S, Bozorgmehr F, Opfermann N, Hoerner-Rieber J, Repka MC, et al. 9-year experience: Prophylactic cranial irradiation in extensive disease small-cell lung cancer. Clin Lung Cancer. 2016; https://doi. org/10.1016/j.cllc.2016.11.012

6. Quan AL, Videtic GMM, Suh JH. Brain metastases in small cell lung cancer. Oncology (Williston Park). 2004; 18:961-72; discussion 974, 979-80, 987. http://www.ncbi.nlm.nih.gov/pubmed/15328892 Accessed 23 Aug 2016

7. Seute $T$, Leffers $P$, ten Velde GPM, Twijnstra A. Neurologic disorders in 432 consecutive patients with small cell lung carcinoma. Cancer. 2004;100:8016. https://doi.org/10.1002/cncr.20043. 
8. Lassen U, Kristjansen PE, Hansen HH. Brain metastases in small-cell lung cancer. Ann Oncol. 1995;6:941-4. http://www.ncbi.nlm.nih.gov/pubmed/ 8624299. Accessed 23 Aug 2016

9. Hochstenbag MM, Twijnstra A, Wilmink JT, Wouters EF, ten Velde GP. Asymptomatic brain metastases (BM) in small cell lung cancer (SCLC): MRimaging is useful at initial diagnosis. J Neurooncol. 2000;48:243-8. http:// www.ncbi.nlm.nih.gov/pubmed/11100822. Accessed 23 Aug 2016

10. Kalemkerian GP, Akerley W, Bogner P, Borghaei H, Chow LQ, Downey RJ, et al. Small cell lung cancer. J Natl Compr Canc Netw. 2013;11:78-98. https:// doi.org/10.6004/JNCCN.2013.0011.

11. Giannone L. Favorable Prognosis of Brain Metastases in Small Cell Lung Cancer. Ann Intern Med. 1987;106:386. https://doi.org/10.7326/0003-4819106-3-386.

12. Kochhar R, Frytak S, Shaw EG. Survival of patients with extensive small-cell lung cancer who have only brain metastases at initial diagnosis. Am J Clin Oncol. 1997;20:125-7. http://www.ncbi.nlm.nih.gov/pubmed/9124183. Accessed 23 Aug 2016

13. Bergqvist $M$, Brattström D, Bennmarker $H$, Wagenius $G$, Riska $H$, Brodin $O$. Irradiation of brain metastases from lung cancer: A retrospective study. Lung Cancer. 1998;20:57-63. https://doi.org/10.1016/S0169-5002(98)00015-4.

14. Postmus PE, Haaxma-Reiche H, Smit EF, Groen HJM, Karnicka H, Lewinski T, et al. Treatment of Brain Metastases of Small-Cell Lung Cancer: Comparing Teniposide and Teniposide With Whole-Brain Radiotherapy-A Phase III Study of the European Organization for the Research and Treatment of Cancer Lung Cancer Cooperative Group. J Clin Oncol. 2000;18:3400-8. http://jco.ascopubs.org/content/18/19/3400.long. Accessed 23 Aug 2016.

15. Bernhardt D, Adeberg S, Bozorgmehr F, Opfermann N, Hoerner-Rieber J, König $L$, et al. Outcome and prognostic factors in patients with brain metastases from small-cell lung cancer treated with whole brain radiotherapy. J Neurooncol. 2017:134

16. Tsao MN, Lloyd N, Wong RKS, Chow E, Rakovitch E, Laperriere N, et al. Whole brain radiotherapy for the treatment of newly diagnosed multiple brain metastases. Cochrane database Syst Rev. 2012; CD003869. doi:https:// doi.org/10.1002/14651858.CD003869.pub3.

17. Tsao MN, Xu W, Wong RK, Lloyd N, Laperriere N, Sahgal A, et al. Whole brain radiotherapy for the treatment of newly diagnosed multiple brain metastases. Cochrane Database Syst Rev. 2018;1:CD003869. doi:https://doi. org/10.1002/14651858.CD003869.pub4.

18. Takahashi T, Yamanaka T, Seto T, Harada H, Nokihara H, Saka H, et al. Prophylactic cranial irradiation versus observation in patients with extensivedisease small-cell lung cancer: a multicentre, randomised, open-label, phase 3 trial. Lancet Oncol. 2017;18:663-71. https://doi.org/10.1016/S14702045(17)30230-9.

19. Micke P, Faldum A, Metz T, Beeh K-M, Bittinger F, Hengstler J-G, et al. Staging small cell lung cancer: Veterans Administration Lung Study Group versus International Association for the Study of Lung Cancer-what limits limited disease? Lung Cancer. 2002;37:271-276. http://www.ncbi.nlm.nih. gov/pubmed/12234695. Accessed 16 Dec 2015.

20. Belkonen S. Hopkins Verbal Learning Test. In: Encyclopedia of Clinical Neuropsychology. New York, NY: Springer New York; 2011. p. 1264-5. https://doi.org/10.1007/978-0-387-79948-3_1127.

21. Barnett JH, Blackwell AD, Sahakian BJ, Robbins TW. The Paired Associates Learning (PAL) Test: 30 Years of CANTAB Translational Neuroscience from Laboratory to Bedside in Dementia Research. In: Current topics in behavioral neurosciences; 2015. p. 449-74. https://doi.org/10.1007/7854_2015_5001.

22. Égerházi A, Berecz R, Bartók E, Degrell I. Automated Neuropsychological Test Battery (CANTAB) in mild cognitive impairment and in Alzheimer's disease. Prog Neuro-Psychopharmacology Biol Psychiatry. 2007;31:746-51. https:// doi.org/10.1016/j.pnpbp.2007.01.011.

23. Bentzen SM, Constine LS, Deasy JO, Eisbruch A, Jackson A, Marks LB, et al. Quantitative Analyses of Normal Tissue Effects in the Clinic (QUANTEC): An Introduction to the Scientific Issues. Int J Radiat Oncol. 2010;76:S3-9. https:// doi.org/10.1016/j.jijobp.2009.09.040.

24. Marks LB, Yorke ED, Jackson A, Ten Haken RK, Constine LS, Eisbruch A, et al. Use of Normal Tissue Complication Probability Models in the Clinic. Int J Radiat Oncol. 2010;76:S10-9. https://doi.org/10.1016/j.jirobp.2009.07.1754.

25. Chang EL, Wefel JS, Hess KR, Allen PK, Lang FF, Kornguth DG, et al. Neurocognition in patients with brain metastases treated with radiosurgery or radiosurgery plus whole-brain irradiation: a randomised controlled trial. Lancet Oncol. 2009;10:1037-44. https://doi.org/10.1016/S14702045(09)70263-3.
26. Van Buuren S. Multiple imputation of discrete and continuous data by fully conditional specification. Stat Methods Med Res. 2007;16:219-42. https://doi. org/10.1177/0962280206074463.

27. Carmichael J, Crane JM, Bunn PA, Glatstein E, Ihde DC. Results of therapeutic cranial irradiation in small cell lung cancer. Int J Radiat Oncol. 1988;14:455-9. https://doi.org/10.1016/0360-3016(88)90260-X.

28. Postmus PE, Haaxma-Reiche H, Gregor A, Groen HJ, Lewinski T, Scolard T, et al. Brain-only metastases of small cell lung cancer; efficacy of whole brain radiotherapy. An EORTC phase II study. Radiother Oncol. 1998;46:29-32. http://www.ncbi.nlm.nih.gov/pubmed/9488124. Accessed 19 Jun 2017.

29. Sperduto PW, Chao ST, Sneed PK, Luo X, Suh J, Roberge D, et al. DiagnosisSpecific Prognostic Factors, Indexes, and Treatment Outcomes for Patients With Newly Diagnosed Brain Metastases: A Multi-Institutional Analysis of 4,259 Patients. Int J Radiat Oncol Biol Phys. 2010;77:655-61.

30. Rades D, Dziggel L, Segedin B, Oblak I, Nagy $V$, Marita A, et al. The first survival score for patients with brain metastases from small cell lung cancer (SCLC). Clin Neurol Neurosurg. 2013;115:2029-32. https://doi.org/10.1016/j. clineuro.2013.06.019.

31. Videtic GMM, Adelstein DJ, Mekhail TM, Rice TW, Stevens GHJ, Lee S-Y, et al. Validation of the RTOG recursive partitioning analysis (RPA) classification for small-cell lung cancer-only brain metastases. Int J Radiat Oncol Biol Phys. 2007;67:240-3. https://doi.org/10.1016/j.ijrobp.2006.08.019.

32. Bernhardt D, Adeberg S, Bozorgmehr F, Opfermann N, Hoerner-Rieber J, König $L$, et al. Outcome and prognostic factors in patients with brain metastases from small-cell lung cancer treated with whole brain radiotherapy. J Neurooncol. 2017; https://doi.org/10.1007/s11060-017-2510-0.

33. Bernhardt D, König L, Aufderstrasse S, Krisam J, Hoerner-Rieber J, Adeberg S, et al. Generation of a New Disease-specific Prognostic Score for Patients With Brain Metastases From Small-cell Lung Cancer Treated With Whole Brain Radiotherapy (BMS-Score) and Validation of Two Other Indices. Clin Lung Cancer. 2017; https://doi.org/10.1016/j.cllc.2017.12.004.

34. Kocher M, Wittig A, Piroth MD, Treuer $H$, Seegenschmiedt $H$, Ruge M, et al. Stereotactic radiosurgery for treatment of brain metastases. A report of the DEGRO Working Group on Stereotactic Radiotherapy. Strahlenther Onkol. 2014;190:521-32. https://doi.org/10.1007/s00066-014-0648-7.

35. Kim K-Y, Sack MN. Parkin in the regulation of fat uptake and mitochondrial biology: emerging links in the pathophysiology of Parkinson's disease. Curr Opin Lipidol. 2012;23:201-5. https://doi.org/10.1097/MOL. 0b013e328352dc5d

36. Linskey ME, Andrews DW, Asher AL, Burri SH, Kondziolka D, Robinson PD, et al. The role of stereotactic radiosurgery in the management of patients with newly diagnosed brain metastases: a systematic review and evidence-based clinical practice guideline. J Neurooncol. 2009;96:45-68. https://doi.org/10. 1007/s11060-009-0073-4.

37. D'Ambrosio AL, DeYoung C, Isaacson SR. Radiosurgical Management of Brain Metastases. Neurosurg Clin N Am. 2011;22:45-51. https://doi.org/10. 1016/j.nec.2010.08.002.

38. Bhangoo SS, Linskey ME, Kalkanis SN. American Association of Neurologic Surgeons (AANS), Congress of Neurologic Surgeons (CNS). Evidence-Based Guidelines for the Management of Brain Metastases. Neurosurg Clin N Am. 2011:22:97-104. https://doi.org/10.1016/j.nec.2010.09.001.

39. Yamamoto M, Serizawa T, Shuto T, Akabane A, Higuchi Y, Kawagishi J, et al. Stereotactic radiosurgery for patients with multiple brain metastases (JLGK0901): a multi-institutional prospective observational study. Lancet Oncol. 2014;15:387-95. https://doi.org/10.1016/S1470-2045(14)70061-0.

40. Bernhardt D, Bozorgmehr F, Adeberg S, Opfermann N, von Eiff D, Rieber J, et al. Outcome in patients with small cell lung cancer re-irradiated for brain metastases after prior prophylactic cranial irradiation. Lung Cancer. 2016;101: 76-81. https://doi.org/10.1016/J.LUNGCAN.2016.09.010.

41. Yomo S, Hayashi M. Is stereotactic radiosurgery a rational treatment option for brain metastases from small cell lung cancer? A retrospective analysis of 70 consecutive patients. BMC Cancer. 2015;15:95. https://doi.org/10.1186/ s12885-015-1103-6.

42. Olson AC, Wegner RE, Rwigema JCM, Heron DE, Burton SA, Mintz AH. Clinical outcomes of reirradiation of brain metastases from small cell lung cancer with Cyberknife stereotactic radiosurgery. J Cancer Res Ther. 2012;8: 411-6. https://doi.org/10.4103/0973-1482.103522.

43. Harris S, Chan MD, Lovato JF, Ellis TL, Tatter SB, Bourland JD, et al. Gamma knife stereotactic radiosurgery as salvage therapy after failure of whole-brain radiotherapy in patients with small-cell lung cancer. Int J Radiat Oncol Biol Phys. 2012;83:e53-9. https://doi.org/10.1016/j.jirobp.2011.11.059. 
44. Nakazaki K, Higuchi Y, Nagano O, Serizawa T. Efficacy and limitations of salvage gamma knife radiosurgery for brain metastases of small-cell lung cancer after whole-brain radiotherapy. Acta Neurochir (Wien). 2013;155:10713; discussion 113-4. https://doi.org/10.1007/s00701-012-1520-0.

45. Li B, Yu J, Suntharalingam M, Kennedy AS, Amin PP, Chen Z, et al.

Comparison of three treatment options for single brain metastasis from lung cancer. Int J Cancer. 2000;90:37-45. https://doi.org/10.1002/(SICl)10970215(20000220)90:1<37::AID-IJC5>3.0.CO;2-7.

Ready to submit your research? Choose BMC and benefit from:

- fast, convenient online submission

- thorough peer review by experienced researchers in your field

- rapid publication on acceptance

- support for research data, including large and complex data types

- gold Open Access which fosters wider collaboration and increased citations

- maximum visibility for your research: over $100 \mathrm{M}$ website views per year 